\title{
Karakterisasi Senyawa Aktif Antioksidan dan Antibakteri Dalam Ekstrak Etanol Buah Namnam (Cynometra cauliflora L.)
}

\author{
Dede Sukandar dan Eka Rizki Amelia \\ Program Studi Kimia Fakultas Sains dan Teknologi UIN Syarif Hidayatullah Jakarta, \\ Jalan Ir. H. Juanda No 95 Ciputat 15412 Indonesia Telp. (62-21) 7493606 \\ email: sukandarkimia@uinjkt.ac.id
}

\begin{abstract}
Abstrak
Telah dilaporkan penelitian untuk mengetahui senyawa yang memiliki aktivitas antioksidan dan antibakteri dalam ekstrak etanol buah namnam (C. cauliflora L.) menggunakan instrumen GC-MS. Hasil analisa GC-MS menunjukkan adanya senyawa 5-hiroksimetilfurfural sebagai komponen utama dalam ekstrak etanol buah namnam. Ekstrak etanol buah namnam memiliki aktivitas antioksidan dengan nilai $\mathrm{IC}_{50}$ sebesar $328,29 \mathrm{ppm}$ dan memiliki aktivitas antibakteri terhadap $E$. coli dan S. aureus dengan zona hambat masing-masing $16 \mathrm{~mm}$ pada konsentrasi $20 \%$.
\end{abstract}

Kata kunci: uji fitokimia, antioksidan, antibakteri, C. cauliflora L., DPPH dan difusi cakram

\begin{abstract}
The research to know of compounds that antioxidant and antibacterial activities from ethanol extract of namnam fruit (C. cauliflora L.) used GC-MS intrument have been reported. Result of GC-MS anlysis have 5-hydroximethilfurfural a mayor compound from namnam fruit ethanol extract. The extract ethanol of namnam fruit has antioxidant activity with value $\mathrm{IC}_{50} 328,29 \mathrm{ppm}$ and antibacterial activity of food pest $E$. coli and $S$. aureus with inhibition area each of $16 \mathrm{~mm}$ at concentration $20 \%$.
\end{abstract}

Keywords: phytochemistry, antioxidant, antibacterial, C. cauliflora L., DPPH and disdiffusion

\section{PENDAhUluan}

Indonesia memiliki sumber daya alam hayati yang sangat beranekaragam dan merupakan sumber senyawa kimia yang tak terbatas jenis dan jumlahnya. Oleh karena itu, keanekaragaman hayati dapat diartikan sebagai keanekaragaman kimiawi yang menghasilkan bahan-bahan kimia untuk kebutuhan manusia seperti obat-obatan, insektisida, kosmetika, dan sebagai bahan dasar sintesa senyawa organik yang lebih bermanfaat (Lenny, 2006).

Satu di antara tanaman yang biasa digunakan sebagai pengobatan tradisional adalah namnam $(C$. cauliflora $\mathrm{L}$.). Namnam atau kopi anjing adalah nama sejenis pohon berbuah dari suku polong-polongan (Leguminosae atau Fabaceae). Tanaman ini merupakan satu di antara jenis tanaman asli Indonesia yang langka. Selain itu, tanaman ini juga tumbuh di Asia tenggara dan India (Verheij dan Coronel, 1997). Namnam yang merupakan tanaman famili leguminosae dilaporkan sebagai penghasil senyawa fenolik yang tersubstitusi gugus hidroksil khususnya golongan oligostilbenoid. Senyawa oligostilbenoid tersebut telah dilaporkan mempunyai beberapa keaktifan biologis yang sangat menarik, seperti antioksidan, anti-HIV, antibakteri, antifungal, dan antihepatotoksik 

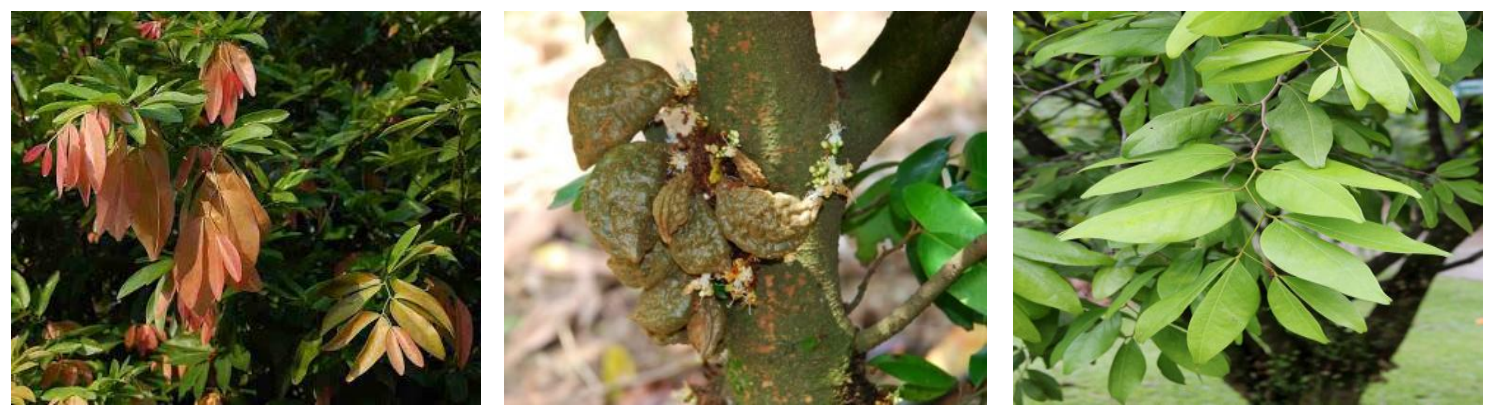

Gambar 1. Namnam (C. cauliflora L.)

(Kristanti, et al, 2006). Penelitian tentang manfaat namnam sangatlah terbatas dan belum diketahui dengan pasti senyawa metabolit yang terkandung di dalamnya.

Namnam merupakan tanaman yang digunakan orang sebagai penghias taman (Gambar 1.). Selain itu, buah namnam banyak digunakan untuk pembuatan asinan, rujak, ataupun campuran sambal karena memiliki rasa yang asam manis dan segar. Sedangkan kayu keras pada bagian tumbuhan ini biasanya digunakan sebagai bahan baku pembuatan mainan anak-anak, yaiu gasing (Heyne, 1987).

Telah dilaporkan sebelumnya bahwa ekstrak etanol buah namnam mengandung senyawa triterpenoid, flavonoid dan saponin. Ekstrak etanol buah namnam juga memiliki aktivitas aktivitas antioksidan dengan nilai $\mathrm{IC}_{50}$ sebesar 328,29 ppm dan aktivitas antibakteri perusak makanan $S$. aureus dan E. coli dengan zona hambat masing-masing sebesar $16 \mathrm{~mm}$ pada konsentrasi 20\% (Adawiyah, et al, 2012).

Berdasarkan latar belakang tersebut, maka perlu dilakukan karakterisasi senyawa yang memiliki aktivitas antioksidan serta antibakteri dari ekstrak etanol buah namnam menggunakan instrumen GC-MS.

\section{METODE PENELITIAN}

Umum. Karakterisasi dilakukan menggunakan instrumen GC-MS Merck Shimadzu QP2010. Sebanyak 0.1 $\mu$ l ektrak etanol buah namnam dimasukkan kedalam kolom HP 5 Polisiloksan $60 \times 0.25 \times 0.25$ dengan kecepatan alir gas pembawa $1 \mathrm{ml} /$ menit dan spilt $100 \mathrm{ml} /$ menit pada tekanan $76.1 \mathrm{kPa}$, suhu oven awal $70^{\circ} \mathrm{C}$ dan akhir $250^{\circ} \mathrm{C}$, suhu detektor $250^{\circ} \mathrm{C}$, suhu injektor $230^{\circ} \mathrm{C}$ dan kecepatan injeksi $0,5 \mathrm{~cm} /$ menit.

Bahan Tumbuhan. Sampel buah namnam (C. cauliflora L.) diperoleh dari di Desa Cintaratu Kecamatan Parigi Kabupaten Pangandaran Jawa Barat.

\section{HASIL DAN PEMBAHASAN}

Hasil GCMS ekstrak etanol buah namnam menunjukkan adanya puncak- puncak serapan dari senyawa aktif yang terkandung dalam ekstrak tersebut. Puncak serapan pada kromatogram hasil analisa GCMS terlihat pada Gambar 2.

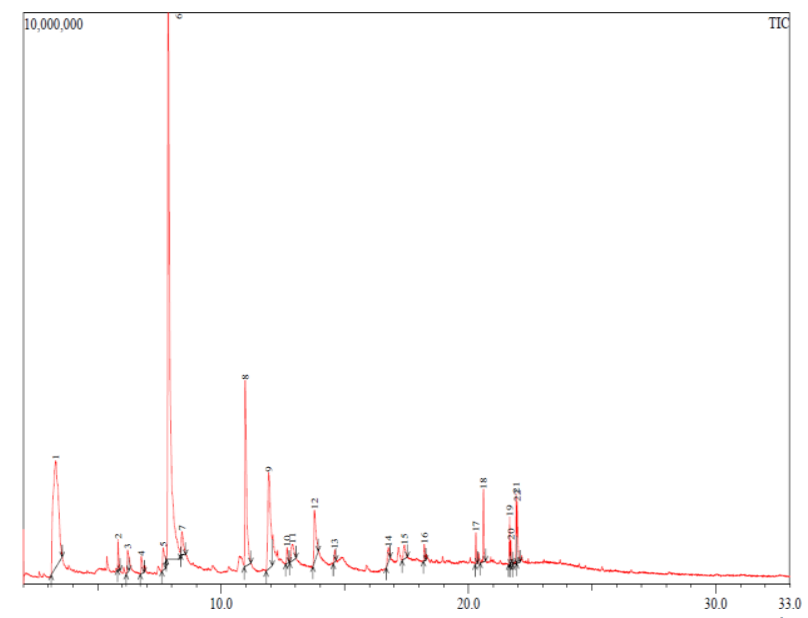

Gambar 2. Kromatogram GC-MS Ekstrak Etanol Buah Nannam 
Berdasarkan data kromatogram GCMS sedikitnya terdapat dua puluh senyawa dalam ekstrak etanol buah namnam. Hasil analisa GCMS kedua puluh senyawa tersebut terlihat pada Tabel 1.

Berdasarkan data pada Wiley7 Library GCMS Merck Shimadzu QP2010, ekstrak etanol buah namnam mengandung gliserol (1) dengan kemiripan $93 \%$, waktu retensi 3,317 , rumus molekul $\mathrm{C}_{3} \mathrm{H}_{8} \mathrm{O}_{3}$ dan berat molekul 92; dimetil malat (2) dengan kemiripan $90 \%$, waktu retensi 5,835, rumus molekul $\mathrm{C}_{6} \mathrm{H}_{10} \mathrm{O}_{5}$ dan berat molekul 162; H-Piran-4-on, 2,3dihidro-3,5-dihidroksi-6 (3) dengan kemiripan $96 \%$, waktu retensi 6,217, rumus molekul $\mathrm{C} 6 \mathrm{H}_{8} \mathrm{O}_{4}$ dan berat molekul 144; Vitamin D3 (4) dengan kemiripan $80 \%$, waktu retensi 6,767, rumus molekul $\mathrm{C}_{2}{ }_{7} \mathrm{H}_{4} \mathrm{O}$ dan berat molekul 384; 5-Hidroksimetilfurfural (5) dengan kemiripan 91\%, waktu retensi 7,867, rumus molekul $\mathrm{C}_{6} \mathrm{H}_{6} \mathrm{O}_{3}$ dan berat molekul 126;
1-Metilurasil (6) dengan kemiripan $79 \%$, waktu retensi 8.417, rumus molekul $\mathrm{C}_{5} \mathrm{H}_{6} \mathrm{~N}_{2} \mathrm{O}_{2}$ dan berat molekul 126; Metil asetoasetat (7) dengan kemiripan $81 \%$, waktu retensi 10,975 , rumus molekul $\mathrm{C}_{5} \mathrm{H}_{8} \mathrm{O}_{3}$ dan berat molekul 116; Asam kojat (8) dengan kemiripan 93\%, waktu retensi 11,925, rumus molekul $\mathrm{C}_{6} \mathrm{H}_{6} \mathrm{O}_{4}$ dan berat molekul 142; Metiletilnitrosamin (9) dengan kemiripan $82 \%$, waktu retensi 12,667 , rumus molekul $\mathrm{C}_{3} \mathrm{H}_{8} \mathrm{~N}_{2} \mathrm{O}$ dan berat molekul 88; D-Allosa (10) dengan kemiripan 89\%, waktu retensi 12,875 , rumus molekul $\mathrm{C}_{6} \mathrm{H}_{12} \mathrm{O}_{6}$ dan berat molekul 180; Trimetil sitrat (11) dengan kemiripan $78 \%$, waktu retensi 13,775 , rumus molekul $\mathrm{C}_{9} \mathrm{H}_{14} \mathrm{O}_{7}$ dan berat molekul 234; Etil ptalat (12) dengan kemiripan 88\%, waktu retensi 14,583, rumus molekul $\mathrm{C}_{12} \mathrm{H}_{14} \mathrm{O}_{4}$ dan berat molekul 222; Semikarbazon 2-metil sikloheksanon (13) dengan kemiripan 71\%, waktu retensi 16,758, rumus molekul $\mathrm{C}_{8} \mathrm{H}_{15} \mathrm{~N}_{3} \mathrm{O}$ dan berat molekul 169; Pirimidin-

Tabel 1. Senyawa Aktif Hasil Analisa GCMS Ekstrak Etanol Buah Namnam

\begin{tabular}{|c|c|c|c|c|c|c|c|c|}
\hline Puncak & $\begin{array}{c}\text { Waktu } \\
\text { Retensi }\end{array}$ & Area & $\begin{array}{c}\% \\
\text { Area }\end{array}$ & Tinggi & $\begin{array}{c}\% \\
\text { Tinggi }\end{array}$ & $\mathrm{A} / \mathrm{T}$ & $\begin{array}{c}\% \\
\text { Kemiripan }\end{array}$ & Nama \\
\hline 1 & 3.301 & 28228178 & 18.45 & 1880469 & 6.81 & 15.01 & 93 & Gliserol \\
\hline 2 & 5.835 & 1081933 & 0.71 & 536137 & 1.94 & 2.01 & 90 & Dimetil malat \\
\hline 3 & 6.217 & 1629693 & 1.06 & 393942 & 1.43 & 4.13 & 96 & $\begin{array}{l}\text { H-Piran-4-on, } \\
\text { dihidro-3,5-dihidroksi-6 }\end{array}$ \\
\hline 4 & 6.767 & 1173790 & 0.77 & 305426 & 1.11 & 3.84 & 80 & Vitamin D3 \\
\hline 5 & 7.867 & 63981123 & 41.81 & 10815156 & 39.19 & 5.92 & 91 & 5-Hidroksimetilfurfural \\
\hline 6 & 8.417 & 2345597 & 1.53 & 404353 & 1.47 & 5.80 & 79 & 1-Metilurasil \\
\hline 7 & 10.975 & 16044682 & 10.48 & 3267812 & 11.84 & 4.90 & 81 & Metil asetoasetat \\
\hline 8 & 11.925 & 13312440 & 8.70 & 1693261 & 6.14 & 7.86 & 93 & Asam kojat \\
\hline 9 & 12.667 & 1013520 & 0.66 & 286604 & 1.04 & 3.53 & 82 & Metiletilnitrosamin \\
\hline 10 & 12.875 & 2394334 & 1.56 & 292626 & 1.06 & 8.18 & 89 & D-Allosa \\
\hline 11 & 13.775 & 5268478 & 3.44 & 906492 & 3.28 & 5.81 & 78 & Trimetil sitrat \\
\hline 12 & 14.583 & 671430 & 0.44 & 218521 & 0.79 & 3.07 & 88 & Etil ftalat \\
\hline 13 & 16.758 & 1268435 & 0.83 & 268972 & 0.97 & 4.71 & 71 & $\begin{array}{l}\text { Semikarbazon } \\
\text { sikloheksanon }\end{array}$ \\
\hline 14 & 17.408 & 1377966 & 0.90 & 246317 & 0.89 & 5.59 & 68 & $\begin{array}{l}\text { Pirimidin-2,4(1H,3H)- } \\
\text { dion 6-hidroksi 5- } \\
\text { metillimino metil }\end{array}$ \\
\hline 15 & 18.217 & 695710 & 0.45 & 290064 & 1.05 & 2.39 & 67 & $\begin{array}{l}\text { Asam 2-okso } \\
\text { siklopentanakarboksilat }\end{array}$ \\
\hline 16 & 20.300 & 946769 & 0.62 & 554593 & 2.01 & 1.70 & 91 & Metil palmitat \\
\hline 17 & 20.605 & 2459711 & 1.61 & 1276922 & 4.63 & 1.92 & 91 & Asam palmitat \\
\hline 18 & 21.667 & 1215208 & 0.79 & 835761 & 3.03 & 1.45 & 91 & Metil linoleat \\
\hline 19 & 21.933 & 2048826 & 1.34 & 1222094 & 4.43 & 1.67 & 90 & Asam linoleat \\
\hline 20 & 21.974 & 2753832 & 1.80 & 1078583 & 3.91 & 2.55 & 81 & 7-Tetradekenal \\
\hline
\end{tabular}


2,4(1H,3H)-dion 6-hidroksi 5-metillimino metil (14) dengan kemiripan 68\%, waktu retensi 17,408, rumus molekul $\mathrm{C}_{6} \mathrm{H}_{7} \mathrm{~N}_{3} \mathrm{O}_{3}$ dan berat molekul 169; Asam 2-okso siklopentanakarboksilat (15) dengan kemiripan $67 \%$, waktu retensi 18,217 , rumus molekul $\mathrm{C}_{7} \mathrm{H}_{10} \mathrm{O}_{3}$ dan berat molekul 142; Metil palmitat (16) dengan kemiripan 91\%, waktu retensi 20,300, rumus molekul $\mathrm{C}_{17} \mathrm{H}_{34} \mathrm{O}_{2}$ dan berat molekul 270; Asam palmitat (17) dengan kemiripan $91 \%$, waktu retensi 20,608, rumus molekul $\mathrm{C}_{16} \mathrm{H}_{32} \mathrm{O}_{2}$ dan berat molekul 256; Metil linoleat (18) dengan kemiripan 91\%, waktu retensi 21,667, rumus molekul $\mathrm{C}_{19} \mathrm{H}_{34} \mathrm{O}_{2}$ dan berat molekul 294; Asam linoleat (19) dengan kemiripan 90\%, waktu retensi 21,933, rumus molekul $\mathrm{C}_{18} \mathrm{H}_{32} \mathrm{O}_{2}$ dan berat molekul 280 dan 7-Tetradekenal (20) dengan kemiripan $81 \%$, waktu retensi 21,975, rumus molekul Menurut Ardiansyah (2007), senyawa antioksidan alami pada tumbuhan umumnya adalah senyawa fenolik atau polifenolik dapat berupa golongan flavonoid, turunan asam sinamat, kumarin, tokoferol dan asam-asam organik polifungsional.

Sedangkan senyawa yang diduga bersifat antibakteri adalah 1-metilurasil (6),
$\mathrm{C}_{14} \mathrm{H}_{26} \mathrm{O}$ dan berat molekul 210.

Senyawa 5-hidroksimetilfurfural (5) diduga merupakan komponen terbanyak dalam ekstrak etanol buah namnam yang memiliki pola fragmentasi sesuai dengan hasil analisa MS pada Gambar 3 dan 4.

Berdasarkan data analisa GC-MS, senyawa yang diduga bersifat antioksidan dalam ekstrak etanol buah namnam antara lain gliserol (1), dimetil malat (2), H-Piran-4-on, 2,3-dihidro-3,5-dihidroksi-6 (3), Vitamin D3 (4), 5-hidroksimetilfurfural (5), Asam kojat (8), Trimetil sitrat (11), Etil ptalat (12), Asam 2-okso siklopentanakarboksilat (15), Asam palmitat (17), Metil linoleat (18) dan Asam linoleat (19). Senyawa-senyawa tersebut termasuk kedalam jenis senyawa fenolik dan asam-asam organik polifungsional yang merupakan senyawa aktif antioksidan. Metiletilnitrosamin (9), Semikarbazon 2-metil sikloheksanon (13), Pirimidin-2,4(1H,3H)-dion 6-hidroksi 5-metillimino metil (14) dan 7Tetradekenal (20). Senyawa-senyawa tersebut merupakan senyawa amina siklik dan alkanal yang dikenal memiliki aktivitas antibakteri.

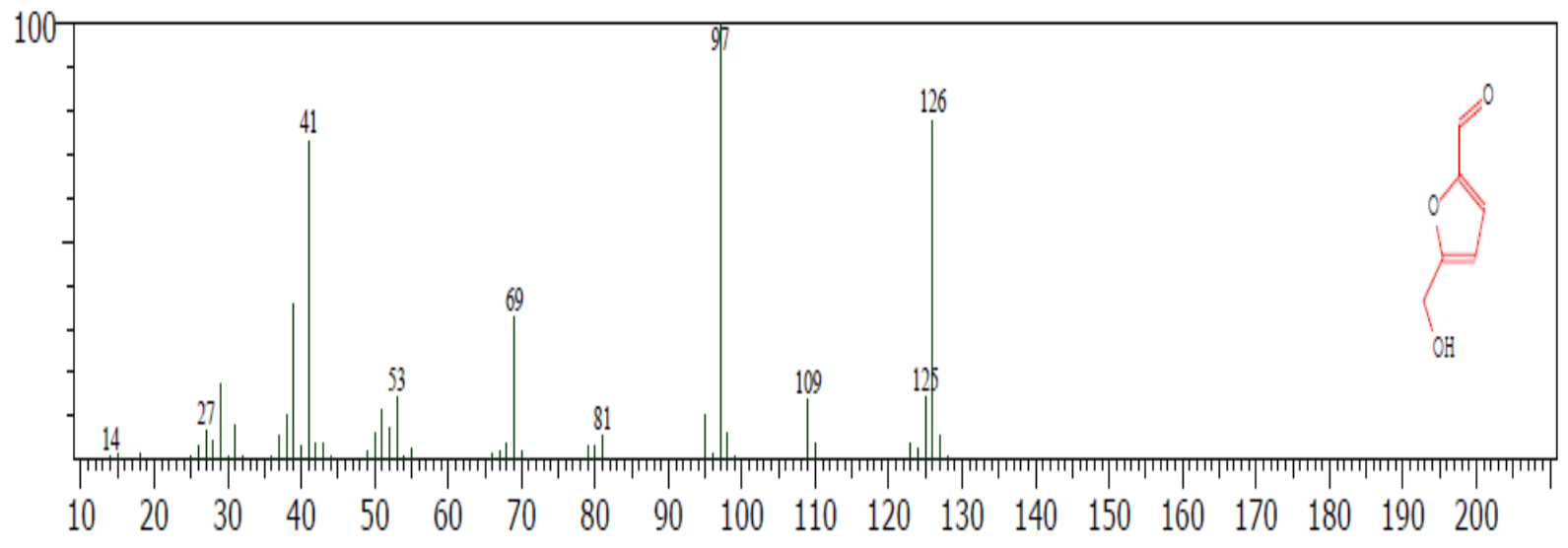

Gambar 3. Hasil Analisa MS Senyawa 5-hidroksimetilfurfural 


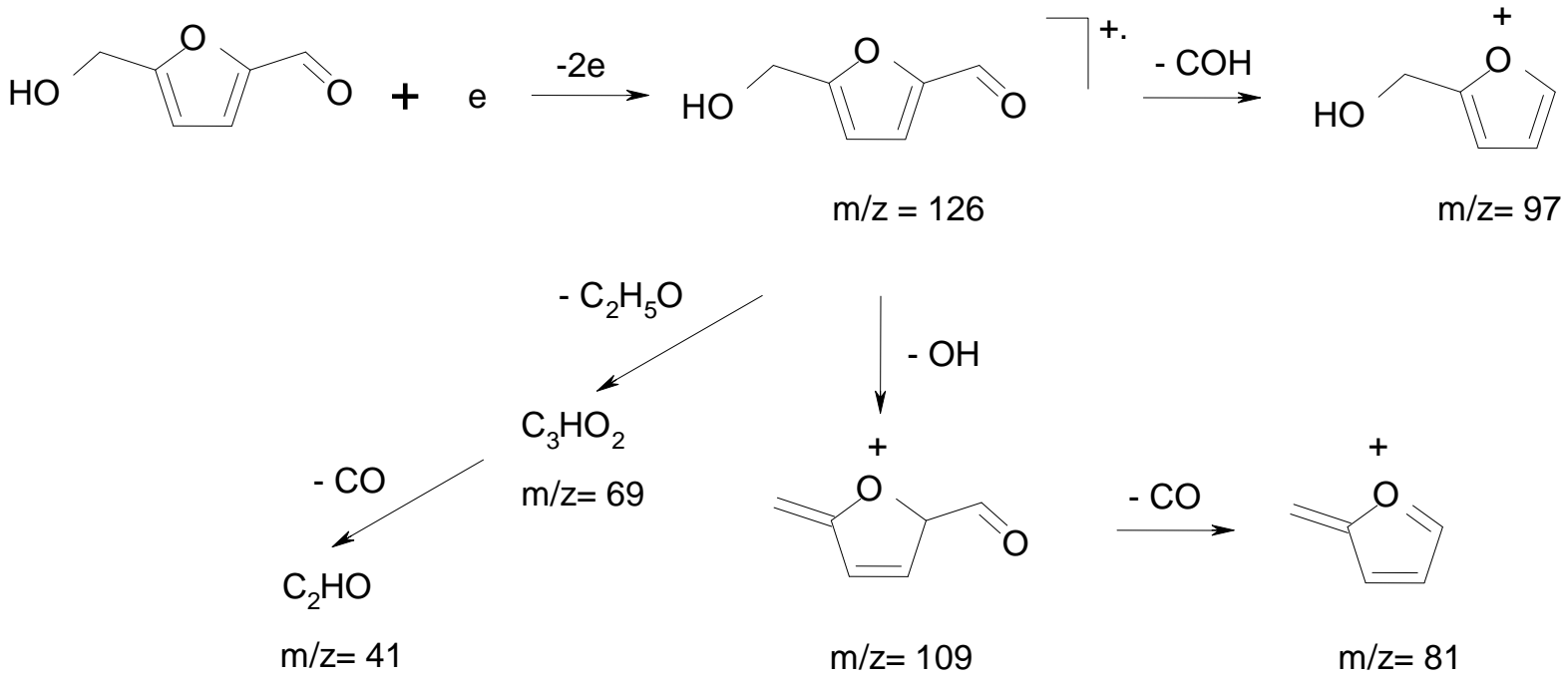

Gambar 4. Pola Fragmentasi Senyawa yang Diduga 5-hidroksimetilfurfural (5)

\section{KESIMPULAN DAN SARAN}

\section{Kesimpulan}

Kesimpulan yang dapat diambil dari penelitian ini yaitu :

a. Ekstrak etanol buah namnam mengandung senyawa golongan triterpenoid, flavonoid dan saponin.

b. Ekstrak etanol buah namnam memiliki aktivitas antioksidan sangat kuat dengan nilai $\mathrm{IC}_{50}$ sebesar 328,29 ppm.

c. Ekstrak etanol buah namnam memiliki komponen utama 5-hidroksimetilfurfural.

\section{Saran}

Penelitian ini merupakan pendahuluan untuk mengetahui aktivitas antioksidan dari ekstrak etanol buah namnam. Oleh karena itu, perlu dilakukan penelitian lebih lanjut mengenai isolasi dan penentuan struktur molekul senyawa aktif antioksidan dan antibakteri dalam ekstrak etaol buah namnam yang didukung data spektroskopi UV-VIS, FTIR, MS, dan NMR.

\section{UCAPAN TERIMA KASIH}

Terima kasih kami ucapkan kepada Dekan Fakultas Sains dan Teknologi UIN Syarif Hidayatullah Jakarta yang telah memberikan bantuan dana penelitian individu tahun anggaran 2012 dan Kepala Pusat Laboratorium Terpadu UIN Syarif Hidayatullah Jakarta yang telah memfasilitasi penelitian ini.

\section{Daftar Pustaka}

Adawiyah, P.Astuti, E.R.Amelia, D.Sukandar, dan S.Hermanto. 2012. Pengujian Fitokimia, Aktivitas Antioksidan dan Antibakteri Ekstrak Etanol Buah Namnam (Cynometra cauliflora L.). Laporan Kegiatan SimNasKBA-2012, 77.

Ardiansyah. 2007. Artikel Iptek: Antioksidan dan Peranannya Bagi Kesehatan. http// www.beritaiptek.com. Diakses pada tanggal 18 November 2007 pukul 09.15 WIB.

Heyne, K. 1987. Tumbuhan Berguna Indonesia. Sarana Wana Jaya, Jakarta

Kristanti, A. F., Nanik, S. A., Mulyadi, T., Yusamsutin, Azizah, dan Dahlia, S. M. 2006. Isolasi Senyawa Antrakuinon dari Cassia multijuga (Leguminosae). Jurnal Kimia Indonesia (Vol. 1 No. 1): hal. 17-21. 
Lenny, S. 2006. Isolasi dan Uji Bioaktivitas Kandungan Kimia Utama Puding Merah dengan Metode Uji Brine Shrimp. USU Repository, Medan.
Verheij, E. W. M. dan Coronel, R. E. 1997. Sumber Daya Nabati Asia Tenggara 2: Buah-buahan yang dapat dimakan. Gramedia, Jakarta. 